\title{
Экспериментальные исследования, моделирование и картографирование природных функций степных ландшафтов Прибайкалья
}

\author{
С. В. Солодянкина ${ }^{冈}$, Ю. В. Вантеева, Т. И. Знаменская \\ Институт географии им. В.Б. Сочавы Сибирского отделения РАН, Российская Федерация \\ (664033, г. Иркутск, ул. Улан-Баторская, 1) \\ Поступила в редакичию 22.08.2019 \\ Принята к публикаиии 26.02.2020
}

\begin{abstract}
Аннотация: Цель статьи - количественно оценить функции формирования фитомассы и регулирования эрозии степных ландшафтов Приольхонья (Прибайкалье) на основе геосистемного подхода с привлечением комплекса экспериментальных методик. Материалы и методы. Дается обзор применяемых в работе экспериментальных методик оценки фитопродукционной и регулирующей функций геосистем. На основе геосистемного подхода результаты исследования экстраполируются на другие участки ландшафта, создаются карты продуктивности ландшафтов и их подверженности водной эрозии. На основе результатов экспериментального и математического моделирования выявляются факторы среды, влияющие на функционирование геосистем в условиях современного хозяйственного использования степных ландшафтов. Результаты и обсуждение. Представлены результаты комплексных ландшафтных исследований экстразональных степей Приольхонского плато (Иркутская область, Россия). В прошлом столетии эта территория подвергалась существенным сельскохозяйственным преобразованиям, и в дополнение со второй половины XX века в прибрежной зоне активно стала развиваться рекреационная деятельность. Зафиксированы невысокие значения запасов травянистой фитомассы, варьирующие от 0,3 т/га до 3,2 т/га. Экспериментальные исследования ветровой эрозии позволили сделать относительную (для разных типов местоположений) оценку объемов переноса вещества, варьирующую от 54 до 245 г/м³. Результаты множественного регрессионного анализа показали, что основными ландшафтными факторами, положительно влияющими на ветровую эрозию, являются: количественное соотношение фракций механического состава верхнего горизонта почвы (чаще всего выражена положительная связь с содержанием ила и пыли) и крутизна склона, а отрицательная связь наиболее выражена с каменистостью почвы и проективным покрытием травянистой растительности. В аридных условиях, которые повлияли на формирование суходольных понижений и концентрацию в них лессовидных и опесчаненных наносов, развитие денудационных процессов обусловлено в первую очередь естественными факторами и усиливается при возрастании антропогенной нагрузки.
\end{abstract}

Ключевые слова: экстразональные степи Приольхонья, фитопродукционная функция, водная эрозия, ветровая эрозия, экспериментальные исследования денудации.

Источник финансирования: Работа выполнена в рамках программы НИР Института географии им. В.Б. Сочавы СО РАН при частичной поддержке Российского фонда фундаментальных исследований в рамках проекта №17-05-00588 А и Русского географического общества в рамках проекта №17-0541020 РГО-РФФИ.

\section{Experimental Studies, Modeling, and Mapping of Natural Functions of the Steppe Landscapes Near Lake Baikal}

\section{S. V. Solodyankina网, Y. V. Vanteeva, T. I. Znamenskaya}

\footnotetext{
() Солодянкина С.В., Вантеева Ю. В., Знаменская Т.И., 2020

E:mail: solodyankinasv@mail.ru

(i) Контент доступен под лицензией Creative Commons Attribution 4.0 License.

The content is available under Creative Commons Attribution 4.0 License.
}

Вестник ВГУ, Серия: География. Геоэкология, 2020, № 1, с. 29-38 


\begin{abstract}
The results of complex landscape studies of the extra-zonal steppes of the Priolkhonsky plateau (Irkutsk Region, Russia) are presented. In the past century, this territory exposed to significant agricultural transformations, and in addition since the second half of the 20th century, recreational activities began to actively develop in the coastal zone. A review of the experimental methods used in the work to assess the geosystem functions: phytomass accumulating and erosion regulation is given. Based on the geosystem approach, results of experimental observations are extrapolated to other parts of the landscape, and maps of productivity and susceptibility to water erosion were made. Based on the results of experimental and mathematical modeling, environmental factors affecting the functioning of geosystems in the context of modern economic use of steppe landscapes are identified. Low values of herbaceous phytomass stocks (from $0.3 \mathrm{t} / \mathrm{ha}$ to $3.2 \mathrm{t} / \mathrm{ha}$ ) were found out. The relative rating of different types of locations by the transferred silt (vary from 54 to $245 \mathrm{~g} / \mathrm{m}^{3}$ ) was made based on experimental studies of wind erosion. The results of multiple regression showed that the main landscape factors that positively affect wind erosion are: the quantitative ratio of the fractions of the mechanical composition of the upper horizon of the soil (the positive relationship with silt and dust is most often) and the steepness of the slope; and the negative relationship is most pronounced with rockiness of soil and projective cover of herbaceous vegetation. Under arid conditions, which influenced the formation of dry depressions and the concentration of loess and sandy sediments in them, the development of denudation processes is primarily due to natural factors and increases by anthropogenic impact.
\end{abstract}

Key words: extrazonal steppes of the Ol'khon region, phytoproductivity function, water erosion, wind erosion, experimental studies of denudation.

Funding: This work was carried out as part of the research program of the Institute of Geography. V.B. Sochava SB RAS with partial support from the Russian Foundation for Basic Research in the framework of project No. 17-05-00588 A and the Russian Geographical Society in the framework of project No. 17-05-41020 RGO-RFBR.

\section{ВВЕДЕНИЕ}

Разработка механизмов регулирования и мер по обеспечению рационального использования и сохранения степных ландшафтов в условиях возрастающей антропогенной нагрузки невозможна без комплексных научных физико-географических исследований.

Территория исследования расположена в центральной части западного побережья озера Байкал в пределах Ольхонского района Иркутской области. Она частично входит в состав Прибайкальского национального парка и находится в пределах центральной экологической зоны Байкальской природной территории, где в соответствии с Федеральным законом «Об охране озера Байкал» № 94-ФЗ от 01.05.1999 установлен особый режим хозяйственной и иной деятельности, обеспечивающий сохранение или улучшение водно-экологической ситуации и потенциала самоочищения ландшафтов.

Значительное развитие здесь получило животноводство, наибольший подъем которого приходился на 70-80-е годы XX века К 2015 году поголовье крупного рогатого скота по отношению к 1980 году сократилось почти в 7 раз [7].

Приоритетной отраслью развития экономики в настоящее время является туризм. Рекреационный потенциал Приольхонья формируется сочетанием относительно благоприятного климата с исключительной пейзажной живописностью, свое- образием и богатством животного и растительного мира, наличием гидроминеральных ресурсов, качеством атмосферного воздуха. Согласно ежегодным статистическим материалам администрации района с 2013 по 2018 годы туристский поток увеличился на $22 \%$. Ежегодно район посещают более 600 тыс. туристов [5].

Приольхонье - уникальный природный комплекс, где представленны экстразональные степи в сочетании с горно-таежными светлохвойными, подтаежными и светлохвойными остепненными лесами. Формирование ландшафтной структуры происходит под влиянием двух основных факторов - Приморского хребта, служащего орографическим барьером на пути движения воздушных масс с запада, и водной массы озера Байкал. Рельеф Приольхонья - денудационный мелкосопочник с абсолютными высотами 456-989,5 м [3]. Климат засушливый с умеренно теплым летом и умеренно холодной малоснежной зимой. Годовое количество осадков минимальное для озера Байкал равно 200-300 мм. Большая их часть выпадает в летний период в виде ливней [9]. Климатические особенности и почвенно-растительные условия способствуют развитию здесь интенсивных процессов денудации [1].

Активное хозяйственное освоение территории за последнее столетие привело не только к обострению конфликтов землепользования, связанных с многофункциональным использованием земель 


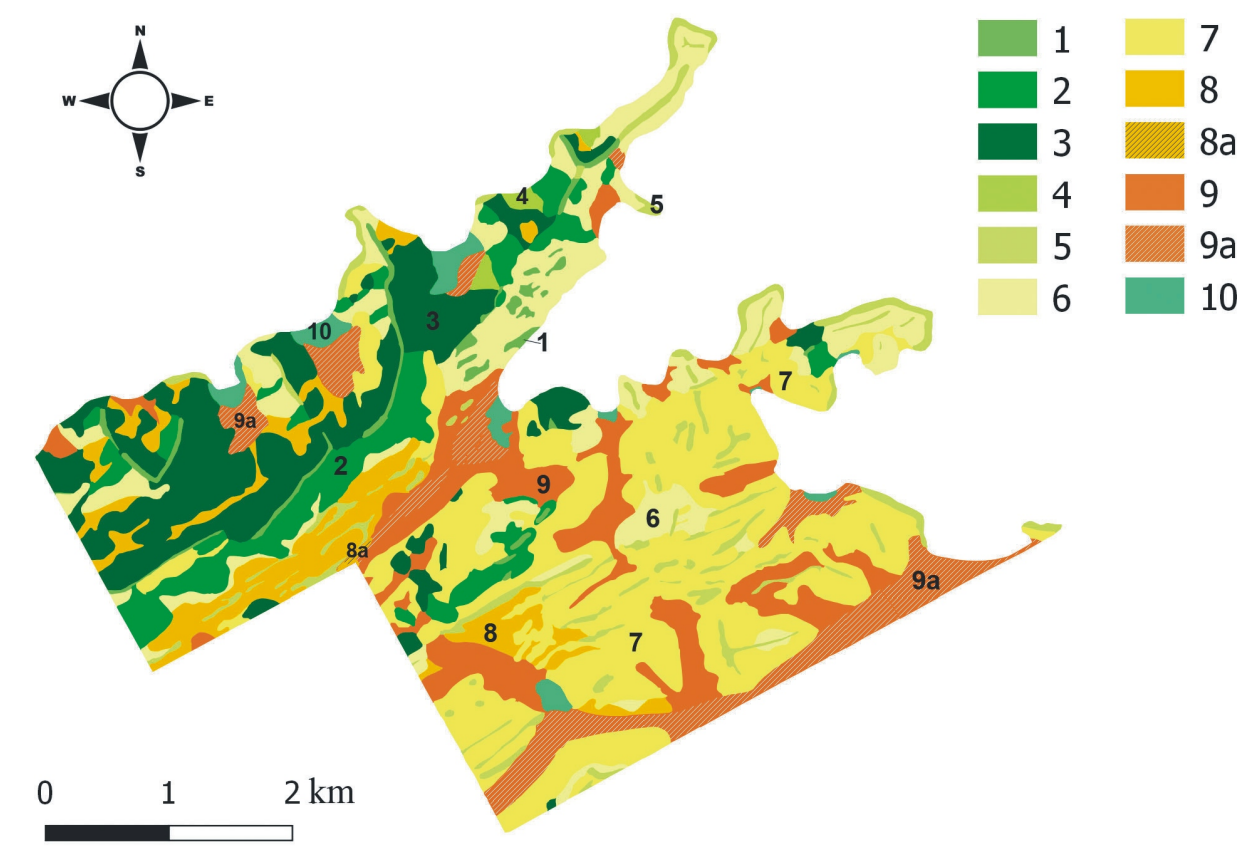

Puc. 1. Геосистемы ключевого участка на Приольхонском плато (группы фаций 1-10)

[Fig. 1. Geosystems of the study area on the Priol'khonsky plateau (group of facies 1-10)]

(природоохранным, селитебным, сельскохозяйственным и рекреационным), но и вызвало деградацию ландшафтов. Рост туристского потока приводит к увеличению участков с высокой плотностью неупорядоченных грунтовых дорог, уплотнению почвы и развитию линейной, плоскостной и ветровой эрозии $[6,22]$. За 10 лет площади застроенной территории увеличились на $6,3 \%$. Коренные степные растительные сообщества частично замещаются на лапчатковые (Potentilla spp.) и полынные (Artemisia monostachya, Artemisia frigida), заболоченные луговины - на пырейные (Elytrigia repens), снижается проективное покрытие растительности и запасы фитомассы [20].

Высокая экологическая, рекреационная и сельскохозяйственная ценность степей Приольхонья, а также их чувствительность к природным катаклизмам и антропогенным воздействиям вызывает необходимость изучения особенностей структуры, функционирования и современного состояния.

\section{МАТЕРИАЛЫ И МЕТОДЫ ИССЛЕДОВАНИЯ}

В основу исследования положен геосистемный подход, предложенный В.Б. Сочавой [8]. Теория иерархической организации геосистем дает возможность соотнести уровни использования земель с соответствующими уровнями ландшафтной дифференциации, что позволяет обосновать принятие решений в сфере землепользования.
Для исследования был выбран ключевой участок в северной части Приольхонского плато, прилегающий к заливу Куркут Малого моря (оз. Бай-

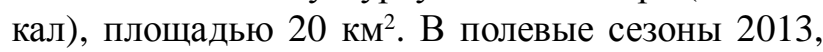
2015, 2017 и 2018 годов выполнено свыше 100 комплексных физико-географических описаний репрезентативных участков, характеризующих разнообразие геосистем территории исследования. Тестовые площадки $(10 \times 10$ м - для степей и лугов, $15 \times 15$ - для леса) закладывались так, чтобы охватить все основные элементы рельефа. На каждой площадке определялись географические координаты точек, особенности рельефа, сообществ травянистой и древесной растительности, почвенные характеристики, водный режим. Анализировались тип и степень антропогенного воздействия: процент вытаптывания и механического повреждения растительного покрова, особенности его видового состава, учитывалась доля тропиночной сети, наличие мусора и кострищ.

Для анализа ландшафтной структуры использовалась карта геосистем Приольхонья (М 1:25 000), составленная на типологическом уровне фаций М. В. Загорской [3]. По данным полевых работ, кадастрового деления территории и анализа данных дистанционного зондирования (SPOT 4, портал Google Earth) карта актуализирована (рис. 1) [18]. 


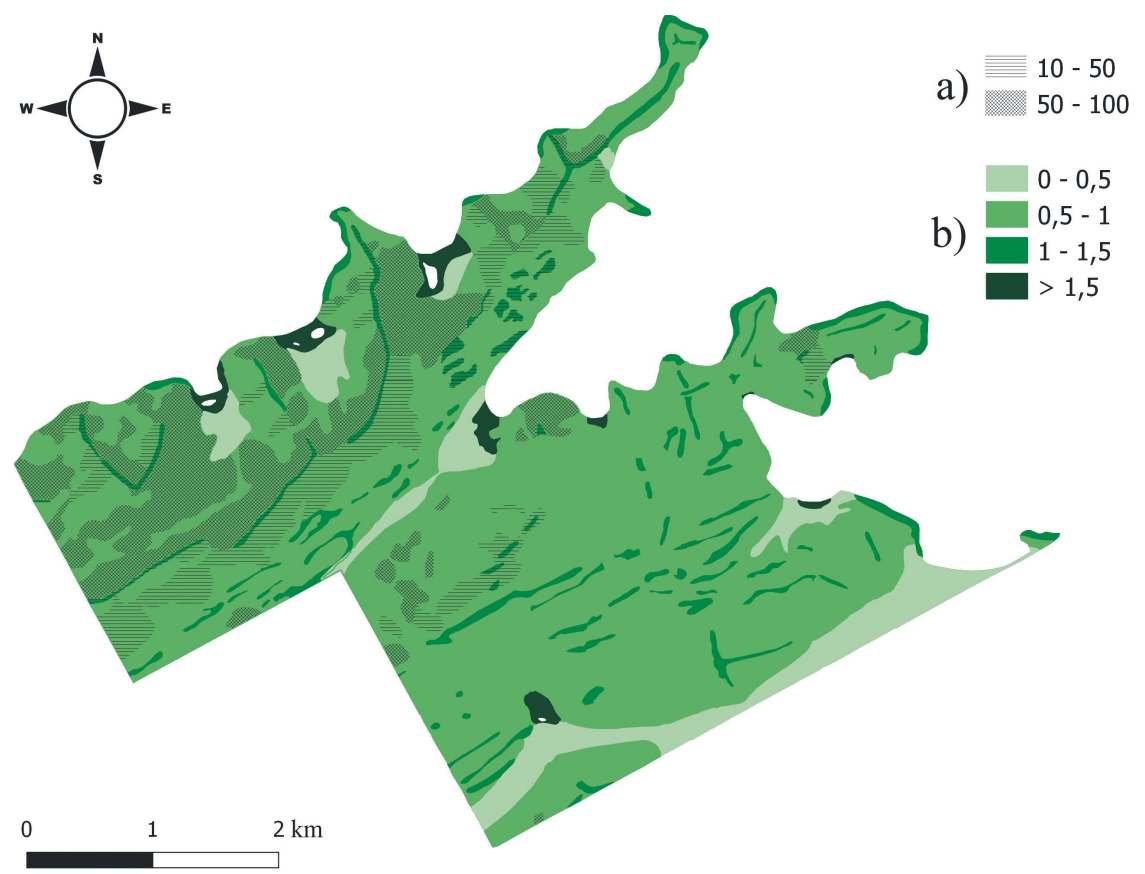

Puc. 2. Запасы фитомассы на ключевом участке: а) древесной (т/га абсолютно сухого вещества); b) травянистой (т/га воздушно-сухого вещества)

[Fig. 2. Phytomass stock on the study area: a) tree phytomass (t/ha of absolutely dry matter); b) herbaceous phytomass ( $\mathrm{t} /$ ha of air dry matter)]

\section{А. СЕВЕРОАЗИАТСКИЕ ГОЛЬЦОВЫЕ И}

\section{ТАЕЖНЫЕ ГЕОСИСТЕМЫ}

\section{А2. Горнотаежные байкало-джугджурские}

Геом І. Подгорные светлохвойные на кристаллосланцах, гнейсах и мраморах

Ia. Класс субксеролитоморфных фациий

1. Крутых склонов редкостойные лиственничные разнотравно-злаковые с выходами горных пород.

2. Крутых склонов преимущественно южной и юго-восточной экспозиции редкостойные лиственничные разнотравно-полынные и разнотравно-злаковые с караганой.

Іб. Класс сублитоморфных фациий

3. Склонов преимущественно северной и северо-западной экспозиции лиственничные с кизильником осоково-типчаково-разнотравные.

Ів. Класс субпсаммоморфных фаций

4. Седловин редкостойные лиственичные разнотравно-злаковые.

\section{В. ЦЕНТРАЛЬНОАЗИАТСКИЕ СТЕПНЫЕ ГЕОСИСТЕМЫ}

\section{В1. Горные Западнозабайкальские}

Геом II. Подгорно-степные на кристаллосланцах, гнейсах и мраморах

IIа. Класс субксеролитоморфных фаций

5. Привершинные и склоновые разнотравнотипчаковые и низкотравные иногда с караганой степи с выходами горных пород.
6. На склонах карагановые злаково-разнотравно-осочковые степи.

7. Склоновые разнотравно-типчаковые степи.

8. Склоновые разнотравно-ковыльные степи; $\mathbf{a}$ - антропогенные модификации.

9. Пологих склонов и межгорных понижений разнотравно-злаковые степи; а - производные разнотравно-полынные и антропогенные модификации (селитебные).

\section{IIг. Класс субгидроморфных фаџий}

10. Межгорных и приозерных понижений заболоченные разнотравно-осоковые луговины.

\section{ОБСУЖДЕНИЕ РЕЗУЛЬТАТОВ}

Особенности фитопродукционной функции геосистем оценивались по запасам травянистой и древесной фитомассы. Для определения надземной фитомассы травостоя применялся метод сбора укосов $[11,15]$ с заложением учетных площадок размером $0,5 \times 0,5$ м. В лабораторных условиях образцы высушивались до воздушно-сухого состояния и взвешивались. Расчет количественных значений запаса древостоя производился методом объемно-конверсионных коэффициентов [4] на основе лесотаксационных характеристик, измеряемых в поле: средний диаметр ствола на высоте 1,3 м от подстилающей поверхности, средняя высота древостоя (м), густота (шт/га) и группа возраста для каждого вида и яруса. 
На основе полученных данных определены значения запаса для каждого типа геосистем (групп фаций). По результатам расчетов фитомассы с использованием ландшафтно-типологической карты в режиме ландшафтно-интерпретационного картографирования составлена карта запасов фитомассы (рис. 2). При этом ландшафтная карта поконтурно переводится в карту нового тематического содержания по алгоритму, основанному на географических знаниях о свойствах геосистем разных типов соответствующего иерархического уровня.

В исследуемых ландшафтах запасы древесной фитомассы низкие. Для подгорных светлохвойных лесов значения варьируют в пределах 10-50 т/га, максимальные запасы (50-100 т/га) отмечаются в лиственничных осоково-типчаково-разнотравных лесах с кизильником в подлеске на склонах северной и северо-западной экспозиции.

Запасы надземной травянистой фитомассы подгорно-степных геосистем варьируют преимущественно в пределах от 0,5 до 1,5 т/га, максимальные значения (более 1,5 т/га) отмечены на заболоченных разнотравно-осоковых луговинах приозерных понижений. Минимальные значения (от 0 до 1 т/га) выявлены в основном для антропогеннонарушенных территорий (производных разнотравно-полынных сообществ и зон распространения спонтанно-сформированных грунтовых дорог и палаточных стоянок, где растительность почти отсутствует). Необходимо отметить, что укосы собирались в сравнительно засушливые годы (2013 и 2015).

Для определения факторов среды, оказывающих влияние на фитопродукционную функцию геосистем, проведен множественный регрессионный анализ данных по запасам надземной травянистой фитомассы. Сообщества восстановительных стадий и селитебных территорий из статистического анализа исключались. В качестве независимых переменных при пошаговом регрессионном анализе рассматривались следующие факторы: 1) экспозиция склонов (град.); 2) высота местоположения (м); 3) крутизна склона (град.); 4) степень увлажнения местоположений (топографический индекс влажности на основе ЦМР, безразмерная величина); 5) степень выпуклости/вогнутости рельефа (характеризует перераспределение гравитационных потоков вещества в пространстве, индекс конвергенции на основе ЦМР, безразмерная величина); 6) мощность гумусового горизонта (см) - по данным полевых описаний.
Объем выборки составил 43 площадки. Наибольшую достоверность показала парная корреляция $\left(R=-0,54 ; R^{2}=0,29 ; t\right.$-критерий Стьюдента $=$ $=-4,06$, достоверность $p=0,9998)$ величины фитопродукционной функции со степенью вогнутости/выпуклости рельефа ( $x$ - индекс конвергенции, безразмерная величина, $y$ - запасы надземной травянистой фитомассы, т/га воздушно-сухого вещества). Уравнение (1) в логарифмическом масштабе имеет следующий вид:

$$
\ln y=-1,38 \ln x+4,23 \text {. }
$$

Результаты регрессионного анализа показали, что среди рассмотренных факторов наибольшее влияние на функцию формирования фитомассы в степях Приольхонья оказывает форма рельефа, отвечающая за перераспределение влаги.

Для исследования эрозионных проиессов применялся комплекс методов, разработанный на основе анализа научных публикаций. Существует большое количество экспериментальных методик исследования ветровой и водной эрозии. Объем отложений обычно измеряют с использованием нивелира и реек, измерение уровня почвенной поверхности чаще осуществляется методом шпилек, либо специальными приборами [14]. Для количественного измерения интенсивности процессов денудации и определения влияющих факторов используют пыле- и пескоуловители, ловушки наносов, фильтры, счетчики для регистрации частиц $[12,19,21]$. Методы стоковых площадок и искусственного дождевания применяются для изучения водной эрозии $[2,13,16,17]$.

В рамках данного исследования измерение дождевого смыва выполнялось специально собранной установкой, имитирующей ливневой дождь и улавливающей переносимый материал [20, 22]. За два года $(2013,2015)$ выполнено 36 измерений (рис. 3). В итоге получены относительные количественные показатели водной эрозии, позволившие проанализировать зависимость этого процесса с учетом ландшафтных характеристик территории. Проведенный статистический анализ собранных данных по водной эрозии показал, что ее основными факторами в Приольхонье являются не только стадия дигрессии почвенного и растительного покрова и крутизна склона, но и опесчаненность (большое количество песка мелкой фракции) верхнего горизонта почвы.

Исследование дефляции проводилось в сентябpe 2017, августе и сентябре 2018 года с помощью комплекса ловушек (пылеуловителей), счетчика частиц (модель DT-9880) и цифрового термоане- 


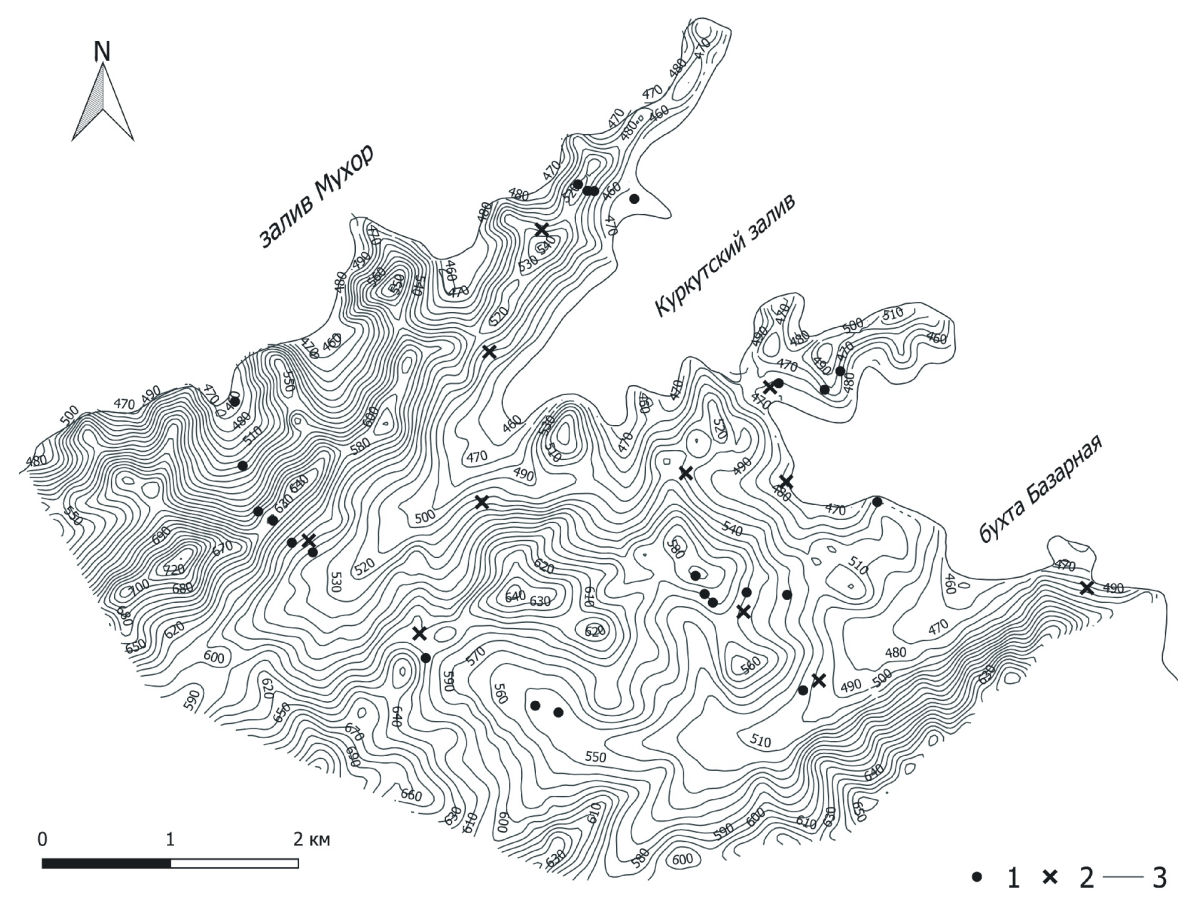

Puc. 3. Схема размещения тестовых площадок экспериментальных исследований: 1 - дождевание; 2 - уловители; 3 - горизонтали с высотой сечения 10 м

[Fig. 3. Test sites for experimental plots: 1 - rainfall simulation; 2 - traps (dust collectors); 3 - horizontals with the vertical interval $10 \mathrm{~m}$ ]

мометра (DT-618) для измерения скорости ветра и температуры воздуха на разных высотах.

На 11 площадках на сутки устанавливались ловушки (рис. 3). На уровне земли устанавливалась ловушка с площадью сечения на поверхнос-

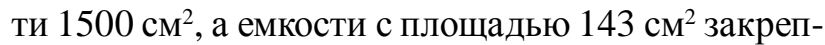
лялись на высотах 30, 60 и 90 см. Собранное за 24 часа вещество взвешивалось, в лабораторных условиях определялись размеры частиц. Пересчет количества переносимого вещества в кубический метр за сутки производился с шагом в 1 см, что позволило сделать относительную (для разных типов местоположений) оценку объемов переноса вещества, варьирующую от 54 до 245 г/м³. Максимальные значения (156,8-245,3 г/м $\left.{ }^{3}\right)$ уловленного в ловушках мелкозема приурочены к пологим склонам и межгорным понижениям с разнотравно-злаковыми степями, что почти в 3 раза выше, чем в селитебной зоне по берегам озера Байкал $\left(93,5\right.$ г/м $\left.{ }^{3}\right)$. Такие высокие значения можно объяснить распространением здесь долин-суходолов, заполняющихся поступающим со склонов рыхлым материалом [10].

Статистический анализ полученных данных показал, что основными факторами влияющими на количество вещества, уловленного наземными ловушками, являются скорость ветра, относительная влажность воздуха и крутизна склона (коэффициент детерминации 0,8 с достоверностью $p=0,993)$; на высоте 60 см выявлена значимая положительная парная корреляция с плотностью почвы, а также с содержанием в верхнем горизонте почвы фракций мелкого песка, средней и мелкой пыли; на высоте 90 см - с плотностью почвы и содержанием фракции средней пыли.

Счетчиком частиц выполнены количественные измерения концентрации частиц (размеры 0.3, 0.5, $1.0,2.5,5$ и 10 мкм) в воздухе на высотах 0.5, 1.5 и 2.0 м от поверхности земли на 69 тестовых площадках. Анализ полученных данных показал, что минимальные значения концентрации всех измеряемых частиц отмечены для тестовых площадок, расположенных на склонах с разнотравно-ковыльной степью, а максимальные - в селитебной зоне. Например, концентрация частиц размером 1 мкм на высоте 0,5 м в разнотравно-ковыльной степи составила 16-88 частиц на один литр воздуха, а на тестовых площадках, расположенных в населенных пунктах и рекреационных местностях варьировала от 48 до 680.

Нами выполнен множественный регрессионный анализ данных, полученных с помощью счетчика частиц в воздухе на высотах $0.5,1.5$ и 2.0 м $(y)$, и набора параметров тестовых площадок $\left(x_{n}\right)$ : 
Зависимость концентрации частиц размером 1.0 мкм на высоте 0,5 м от поверхности земли от влияющих факторов

[Table. The dependence of the concentration of particles with a size of $1.0 \mu \mathrm{m}$ at a height of $0.5 \mathrm{~m}$ from the ground surface on influencing factors]

\begin{tabular}{|l|c|c|c|c|c|}
\hline Переменные [Variables] & $\begin{array}{c}\text { Коэффи- } \\
\text { циенты } \\
\text { [Coeffi- } \\
\text { cient] }\end{array}$ & $\begin{array}{c}\text { Стандартное } \\
\text { отклонение } \\
\text { [Standard } \\
\text { deviation] }\end{array}$ & $\begin{array}{c}t \text {-критерий } \\
\text { [t-test] }\end{array}$ & $\begin{array}{c}p \text { (достовер- } \\
\text { ность) } \\
\text { [p-value] }\end{array}$ & $R^{2}$ \\
\hline Константа & -11171 & 3156,6 & $-3,5$ & 0,999 & \\
\hline$x_{1}-$ средняя скорость ветра & 12,6 & 3,4 & 3,7 & $>0,999$ & 0,09 \\
\hline$x_{2}-$ крутизна склона & 9,8 & 1,7 & 5,6 & $>0,999$ & 0,09 \\
\hline $\begin{array}{l}x_{3}-\text { проективное покрытие } \\
\text { травянистого яруса }\end{array}$ & $-1,4$ & 0,3 & $-5,4$ & $>0,999$ & 0,03 \\
\hline$x_{4}-$ проективное покрытие \\
древесного яруса & $-8,7$ & 2,5 & $-3,5$ & 0,999 & 0,03 \\
\hline$x_{5}-1-0,25$ & 108,0 & 31,3 & 3,45 & 0,999 & 0,07 \\
\hline$x_{6}-0,25-0,05$ & 109,5 & 31,2 & 3,5 & 0,999 & 0,03 \\
\hline$x_{7}-0,05-0,01$ & 109,4 & 31,5 & 3,5 & 0,999 & 0,06 \\
\hline$x_{8}-0,01-0,005$ & 111,8 & 31,5 & 3,5 & 0,999 & 0,05 \\
\hline$x_{9}-0,005-0,001$ & 104,1 & 30,2 & 3,4 & 0,999 & 0,02 \\
\hline$x_{10}-<0,001$ мм & 122,1 & 32,2 & 3,8 & $>0,999$ & 0,12 \\
\hline$x_{11}-3-1$ мм & $-2,1$ & 0,7 & $-2,9$ & 0,994 & 0,16 \\
\hline$x_{12}->3$ мм & $-4,3$ & 0,8 & $-5,1$ & $>0,999$ & 0,02 \\
\hline$x_{13}-$ плотность почвы & 180,6 & 41,0 & 4,4 & $>0,999$ & 0,03 \\
\hline
\end{tabular}

проективное покрытие травянистого и древесного ярусов (\%), температура воздуха $\left({ }^{\circ} \mathrm{C}\right)$, относительная влажность воздуха (\%), скорость ветра (максимальная и средняя, м/с), крутизна склона $\left({ }^{\circ}\right)$, плотность почвы $\left(г / \mathrm{cm}^{3}\right)$, а также содержание в верхнем горизонте почвы: органического углерода $(\%)$; фракций песка в \% $(0,05-0,25 ; 0,25-0,5 ; 0,5-$ 1,0 мм), пыли (0,001-0,005;0,005-0,01;0,010,05 мм) и ила (<0,001 мм), каменистости (> 3 мм).

Статистический анализ проведен для 18 зависимых переменных (по 50 измерений для каждой). Предварительно выполнен парный корреляционный анализ для проверки независимых переменных. Затем производился множественный линейный регрессионный анализ, рассчитывались бетакоэффициенты ( $\beta$ ).

Например, для концентрации частиц размером 1,0 мкм на высоте 0,5 м от поверхности земли наибольшую достоверность показало следующее уравнение (2) множественной регрессии $(R=0,85$; $R^{2}=0,73$; критерий Фишера $\left.F=7,5 ; p>0,999\right)$ :

$$
\begin{gathered}
y=12,6 x_{1}+9,8 x_{2}-1,4 x_{3}-8,7 x_{4}+108 x_{5}+ \\
+109,4 x_{6}+109,4 x_{7}+111,8 x_{8}+104,1 x_{9}+ \\
+122,1 x_{10}-2,1 x_{11}-4,3 x_{12}+180,6 x_{13}-11171 .
\end{gathered}
$$

Переменные и статистические параметры уравнения представлены в таблице. Установлено, что концентрация частиц размером 1 мкм связана с широким набором факторов: наибольший положительный вклад с разной степенью влияния вносит количество песка и пыли различных фракций в верхнем горизонте почвы (тонкий песок $\beta=40,9$, крупная пыль $\beta=22,7$, средний и крупный песок $\beta=19,1$, ил $\beta=10,9$, средняя и мелкая пыль $\beta=8,5$ и 8,1 соответственно). Менее выражено влияние крутизны склона, каменистости и плотности почвы, проективного покрытия древесного и травянистого покрова и средней скорости ветра.

В целом результаты множественного регрессионного анализа показали, что основными факторами, влияющими на концентрацию частиц в воздухе на высотах 0,5-2 м, являются: количественное соотношение фракций механического состава верхнего горизонта почвы (чаще всего выражена положительная связь с содержанием ила и пыли) и крутизна склона. Отрицательная связь чаще всего наиболее выражена с каменистостью почвы и проективным покрытием травянистого покрова.

\section{ЗАКЛЮЧЕНИЕ}

Представленные в статье результаты исследования получены с применением комплекса методов: натурных физико-географических и экспериментальных наблюдений, ландшафтного и ланд- 
шафтно-интерпретационного картографирования, геоинформационного и статистического анализа. Сформировано представление о пространственной структуре ландшафтов Приольхонья. Количественно определены значения исследуемых природных функций (продукционных и регулирующих). Выявлены особенности их изменчивости в соответствии с ландшафтной структурой и влияющие факторы.

По результатам исследований получена количественная оценка фитопродукционной функции геосистем Приольхонья, зафиксированы невысокие значения запасов травянистой фитомассы, варьирующие от 0,3 т/га до 3,2 т/га в период наблюдения.

При полевых и экспериментальных работах выполнена количественная оценка процессов денудации в границах ландшафтов Приольхонья. В аридных условиях, которые повлияли на формирование суходольных понижений и концентрацию в них лессовидных и опесчаненных наносов, на делювиальных, реже пролювиальных, отложениях, развитие денудационных процессов обусловлено в первую очередь естественными факторами и усиливается при возрастании антропогенной нагрузки.

Распространение площадной и линейной эрозии приводит к нарушению целостности современных ландшафтов Приольхонья, что заметно снижает их эксплуатационное значение. Экспериментальные наблюдения за переносом вещества позволяют получить количественную оценку значений и скорости эрозионных процессов в разных условиях и могут послужить обоснованием для выбора природоохранных мероприятий.

Рекультивация антропогенно-трансформированных участков степей и сохранение коренных степных сообществ является необходимым условием для повышения фитопродукционной функции и восстановления естественных механизмов регулирования эрозионных процессов в ландшафтах Приольхонья.

\section{СПИСОК ЛИТЕРАТУРЫ}

1. Агафонов Б.П. Распространение и прогноз физико-географических процессов в Байкальской впадине // Динамика Байкальской впадины. Новосибирск, Наука, 1975, с. 59-138.

2. Егоров Ю.В., Бобков А.В., Есафова Е.Н., Флесс А. Д. Устройство для учета твердого и жидкого при ливневой эрозии // Почвоведение, 2015, № 2, с. 239-243.

3. Загорская М.В. Ландшафтная структура Центрального Приольхонья // География и природные ресурсы, 2004, № 4, с. 58-68.
4. Замолодчиков Д.Г., Уткин А.М., Коровин Г.Н. Конверсионные коэффициенты фитомасса/запас в связи с дендрометрическими показателями и составом древостоя // Лесоведение, 2005, № 6, с. 78-81.

5. История района. Администрация. Ольхонское районное муниципальное образование, 2018. Доступно: http://xn----8sbwecbgqgbbhxj1dvg.xn--p1ai/istoriyarayona.html. (дата обращения 30.05.2019).

6. Караваев В. А., Опекунова М.Ю., Солодянкина С. В., Знаменская Т. И., Вантеева Ю. В. Влияние рекреационного освоения на линейную эрозию в Приольхонье // Геоморфология, 2019, № 1, с. 93-104.

7. Семенов Ю. М., Антипов А. Н., Буфал В. В. Экологически ориентированное планирование землепользования в байкальском регионе. Ольхонский район. Иркутск, Изд-во Институга географии СО РАН, 2004. 147 с.

8. Сочава В.Б. Введение в учение о геосистемах. Новосибирск, Наука, 1978. 319 с.

9. Трофимова И.Е. Типизация и картографирование климатов Байкальской горно-котловинной системы // География и природные ресурсы, 2002, № 2, с. 53-61.

10. Уфимцев Г. Ф., Сковитина Т. М., Филинов И. А., Щетников А.А. Особенности рельефа Приольхонья // География и природные ресурсы, 2010, № 4, с. 56-62.

11. Deak B., Valko O., Kelemen A., Torok P., Miglecz T., Olvedi T., Lengyel S., Tothmeresz B. Litter and graminoid biomass accumulation suppresses weedy forbs in grassland restoration // Plant Biosystems, 2011, v. 145, pp. 730-737.

12. Goossens D., Offer Z.Y. Wind tunnel and field calibration of six aeolian dust samplers // Atmospheric Environment, 2000, v. 34(7), pp. 1043- 1057.

13. Grismer M.E. Standards vary in studies using rainfall simulators to evaluate erosion // California Agriculture, 2012, v. 66 (3), pp. 102-107.

14. Hai C.X., Liu B., Zhao Y., Du P.F., Yuan X. Y., Jiang H.T., Zhou R.R., Wang J. A New Instrument for Testing Wind Erosion by Soil Surface Shape Change // Applied and Environmental Soil Science, 2009, v. 2009, pp. 1-3. Доступно: https://www.hindawi.com/journals/aess/ 2009/491570/ (дата обращения 15.05.2019)

15. Kelemen A., Torok P., Valko O., Miglecz T., Tothmeresz B. Mechanisms shaping plant biomass and species richness: plant strategies and litter effect in alkali and loess grasslands // Journal of Vegetation Science, 2013, v. 24 , pp. $1195-1203$.

16. Pirson F., Williams J., Al-Hamdan O. SageSTEP Pinyon-Juniper Hydrology: Implications for Rangeland CEAP for Rangeland, 2010. Доступно: http:// www.sagestep.org/events/ ut_rsch_mtg_10/ppts/ Pierson_Hydro.pdf. (дата обращения 15.05.2019)

17. Ries J.B., Langer M. Runoff generation of abandoned fields in the Central Ebro Basin. Results from rainfall simulation experiments. In: Garcia-Ruiz J.M., Jones J. A. A. \& Arnaez J. [edrs.]: Environmental Change and Water Sustainability, Instituto Pirenaico de Ecologia; Zaragoza, 2002, pp. 65-81. 
18. Solodyankina S. V., Znamenskaya T.I., Vanteeva J.V., Opekunova M.Yu. Geosystem approach for assessment of soil erosion in Priol'khonie steppe (Siberia) // IOP Conference Series: Earth and Environmental Science, 2018, v. 201, pp. 1-6.

19. Van Donk S. J., Skidmore E. L. Field Experiments for Evaluating Wind Erosion Models // Annals of Arid Zone, 2001, v. 40(3), pp. 281-302.

20. Vanteeva J. V., Solodyankina S. V. Ecosystem functions of steppe landscapes near Lake Baikal // Hacquetia, 2015, v. 14(1), pp. 65-78.

21. Webb N., Herrick J., Van Zee J., Hugenholtz C., Zobeck T., Okin G., Standard Methods for Wind Erosion Research and Model Development, 2015. Доступно: https:/ /winderosionnetwork.org/files/NetworkManual.pdf. (дата обращения 16.05.2019).

22. Znamenskaya T.I., Vanteeva Yu. V., Solodyankina S. V. Factors of the Development of Water Erosion in the Zone of Recreation Activity in the Ol'khon Region // Eurasian Soil Science, 2018, v. 51(2), pp. 228-235.

\section{REFERENCES}

1. Agafonov B.P. Rasprostraneniye i prognoz fizikogeograficheskikh protsessov v Baykalskoy vpadine [Distribution and prognosis of physical and geographical processes in the Baikal depression]. Dinamika Baykalskoy vpadiny. Novosibirsk, Nauka, 1975, pp. 59-138. (In Russ.)

2. Egorov Yu. V., Bobkov A.V., Esafova E.N., Fless A.D. Ustroystvo dlya ucheta tverdogo i zhidkogo pri livnevoy erozii [Device for measuring solid and liquid during rainfall erosion]. Pochvovedeniye, 2015, no. 2, pp. 239243. (In Russ.)

3. Zagorskaya. M. V. Landshaftnaya struktura Tsentralnogo Priolkhonia [Landscape structure of the Central Priolkhonie] // Geografiya i prirodnyye resursy, 2004, no. 4, pp. 58-68. (In Russ.)

4. Zamolodchikov D. G., Utkin A.M., Korovin G.N. Konversionnyye koeffitsiyenty fitomassa/zapas v svyazi s dendrometricheskimi pokazatelyami i sostavom drevostoya [Conversion factors phytomass / stock in connection with dendrometric indicators and composition of the tree stand] // Lesovedeniye, 2005, no. 6, pp. 78-81. (In Russ.)

5. Istoriya rayona. Administratsiya. Olkhonskoye rayonnoye munitsipalnoye obrazovaniye. 2018. Available at: http://xn----8sbwecbgqgbbhxj1dvg.xn--p1ai/istoriyarayona.html (accessed date 30.05.2019). (In Russ.)

6. Karavayev V.A., Opekunova M. Yu., Solodyankina S.V., Znamenskaya T. I., Vanteyeva Yu. V. Vliyaniye rekreatsionnogo osvoyeniya na lineynuyu eroziyu v Priolkhonye [The impact of recreational development on linear erosion in the Priolkhonye]. Geomorfologiya, 2019, no. 1, pp. 93-104. (In Russ.)

7. Semenov Yu. M., Antipov A. N., Bufal V. V. Ekologicheski oriyentirovannoye planirovaniye zemlepolzovaniya $v$ baykalskom regione. Olkhonskiy rayon [Environmentally oriented land use planning in the Baikal region. Olkhonsky district]. Irkutsk, Izdatelstvo Instituta geografii SO RAN, 2004. 147 pp. (In Russ.)
8. Sochava V.B. Vvedeniye v ucheniye o geosistemakh [Introduction to the geosystems approach]. Novosibirsk, Nauka, 1978. 319 pp. (In Russ.)

9. Trofimova I.E. Tipizatsiya i kartografirovaniye klimatov Baykalskoy gorno-kotlovinnoy sistemy [Typification and mapping of climates of the Baikal mountain basin system]. Geografiya i prirodnyye resursy, 2002, no. 2, pp. 5361. (In Russ.)

10. Ufimtsev G.F., Skovitina T.M., Filinov I. A., Shchetnikov A. A. Osobennosti relyefa Priolkhonia [Landforms of Priolkhonye]. Geografiya i prirodnyye resursy, 2010, no. 4, pp. 56-62. (In Russ.)

11. Deak B., Valko O., Kelemen A., Torok P., Miglecz T., Olvedi T., Lengyel S., Tothmeresz B. Litter and graminoid biomass accumulation suppresses weedy forbs in grassland restoration. Plant Biosystems, 2011, v. 145, pp. 730-737.

12. Goossens D., Offer Z. Y. Wind tunnel and field calibration of six aeolian dust samplers. Atmospheric Environment, 2000, v. 34(7), pp. 1043- 1057.

13. Grismer M.E. Standards vary in studies using rainfall simulators to evaluate erosion. California Agriculture, 2012, v. 66 (3), pp. 102-107.

14. Hai C.X., Liu B., Zhao Y., Du P.F., Yuan X.Y., Jiang H. T., Zhou R. R., Wang J. A New Instrument for Testing Wind Erosion by Soil Surface Shape Change. Applied and Environmental Soil Science, 2009, v. 2009, pp. 1-3. Available at: https://www.hindawi.com/journals/aess/2009/ 491570/ (accessed date 15.05.2019)

15. Kelemen A., Torok P., Valko O., Miglecz T., Tothmeresz B. Mechanisms shaping plant biomass and species richness: plant strategies and litter effect in alkali and loess grasslands. Journal of Vegetation Science, 2013, v. 24, pp. 1195-1203.

16. Pirson F., Williams J., Al-Hamdan O. SageSTEP Pinyon-Juniper Hydrology: Implications for Rangeland CEAP for Rangeland, 2010. Available at: http:// www.sagestep.org/events/ ut_rsch_mtg_10/ppts/ Pierson_Hydro.pdf. (accessed date 15.05.2019)

17. Ries J.B., Langer M. Runoff generation of abandoned fields in the Central Ebro Basin. Results from rainfall simulation experiments. In: Garcia-Ruiz J.M., Jones J. A. A. \& Arnaez J. [edrs.]: Environmental Change and Water Sustainability, Instituto Pirenaico de Ecologia; Zaragoza, 2002, pp. 65-81.

18. Solodyankina S.V., Znamenskaya T.I., Vanteeva J. V., Opekunova M. Yu. Geosystem approach for assessment of soil erosion in Priol'khonie steppe (Siberia) // IOP Conference Series: Earth and Environmental Science, 2018, v. 201, pp. 1-6.

19. Van Donk S. J., Skidmore E. L. Field Experiments for Evaluating Wind Erosion Models. Annals of Arid Zone, 2001, v. 40(3), pp. 281-302.

20. Vanteeva J. V., Solodyankina S. V. Ecosystem functions of steppe landscapes near Lake Baikal. Hacquetia, 2015 , v. $14(1)$, pp. 65-78.

21. Webb N., Herrick J., Van Zee J., Hugenholtz C., Zobeck T., Okin G., Standard Methods for Wind Erosion 
Research and Model Development, 2015. Available at: https://winderosionnetwork.org/files/NetworkManual.pdf. (accessed date 16.05.2019).

\section{КОНФЛИКТ ИНТЕРЕСОВ}

Авторы декларируют отсутствие явных и потенциальных конфликтов интересов, связанных с публикацией настоящей статьи.

Солодянкина Светлана Викторовна

кандидат географических наук, старший научный сотрудник лаборатории теоретической географии Института географии им. В.Б. Сочавы СО РАН, г. Иркутск, Российская Федерация, ORCID: 0000-0001-5958-9882, E-mail: solodyankinasv@ mail.ru

Вантеева Юлия Владимировна

кандидат географических наук, научный сотрудник лаборатории теоретической географии Института географии им. В. Б. Сочавы СО РАН, г. Иркутск, Российская Федерация, ORCID: 0000-0002-5735-7989, E-mail: ula.vant@mail.ru

Знаменская Татьяна Игоревна

кандидат географических наук, научный сотрудник лаборатории геохимии ландшафтов и географии почв Института географии им. В. Б. Сочавы СО РАН, г. Иркутск, Российская Федерация, ORCID: https:// orcid.org/0000-0002-7623-161x, E-mail: tiznam@mail.ru
22. Znamenskaya T.I., Vanteeva Yu. V., Solodyankina S. V. Factors of the Development of Water Erosion in the Zone of Recreation Activity in the Ol'khon Region. Eurasian Soil Science, 2018, v. 51(2), pp. 228-235.

\section{CONFLICT OF INTEREST}

The authors declare no information of obvious and potential conflicts of interest related to the publication of this article.

Svetlana V. Solodyankina

Cand. Sc. (Geogr.), Senior researcher of laboratory of theoretical geography V.B. Sochava Institute of Geography SB RAS, Irkutsk, Russian Federation, ORCID: https://orcid.org/0000-0001-5958-9882, E-mail: solodyankinasv@mail.ru

Yuliya V. Vanteeva

Cand. Sc. (Geogr.), Researcher of laboratory of theoretical geography V.B. Sochava Institute of Geography SB RAS, Irkutsk, Russian Federation, ORCID: https://orcid.org/ 0000-0002-5735-7989, E-mail: ula.vant@mail.ru

Tatyana I. Znamenskaya

Cand. Sc. (Geogr.), Researcher of laboratory of landscape geochemistry V.B. Sochava Institute of Geography SB RAS, Irkutsk, Russian Federation, ORCID: https://orcid.org/0000-0002-7623-161x, E-mail: tiznam@mail.ru 